\title{
Tandem communication improves ant foraging success in a highly competitive tropical habitat
}

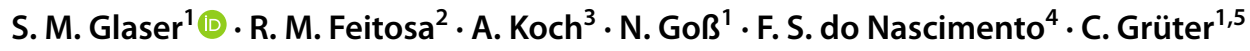

Received: 25 August 2020 / Revised: 10 January 2021 / Accepted: 6 February 2021 / Published online: 9 March 2021

(c) The Author(s) 2021

\begin{abstract}
Tropical ants experience intense intra- and interspecific competition for food sources, which influences their activity pattern and foraging strategies. Even though different ant species can coexist through spatial and temporal niche partitioning, direct competition for food cannot be avoided. Recruitment communication is assumed to help colonies to monopolize and exploit food sources successfully, but this has rarely been tested under field conditions. We studied if recruitment communication helps colonies of the Neotropical ant Pachycondyla harpax to be more successful in a highly competitive tropical environment. Additionally, we explored if temporal and spatial niche differentiation helps focal colonies to avoid competition. Pachycondyla harpax competed with dozens of ant species for food. Mass-recruiting competitors were often successful in displacing $P$. harpax from food baits. However, when foragers of $P$. harpax were able to recruit nestmates they had a 4-times higher probability to keep access to the food baits. Colonies were unlikely to be displaced during our observations after a few ants arrived at the food source. Competition was more intense after sunset, but a disproportionate increase in activity after sunset allowed focal colonies to exploit food sources more successfully after sunset. Our results support the hypothesis that recruitment communication helps colonies to monopolize food sources by helping them to establish a critical mass of nestmates at large resources. This indicates that even species with a small colony size and a slow recruitment method, such as tandem running, benefit from recruitment communication in a competitive environment.
\end{abstract}

Keywords Ant $\cdot$ Competition $\cdot$ Pachycondyla harpax $\cdot$ Recruitment $\cdot$ Tandem running

\section{Introduction}

The tropics are home to thousands of ant species, some forming colonies containing millions of ants. Collectively, their biomass exceeds the biomass of all wild mammals combined (Bar-On et al. 2018) as they fulfill vital ecological roles as predators, herbivores or soil architects (Hölldobler and Wilson 1990; Davidson et al. 2003). Competition for food sources among colonies can be intense, but intra- and interspecific competition is often reduced through a variety of mechanisms (Hölldobler 1981). Often species occupy particular dietary niches, e.g. by exploiting different food types (sugars, carrion, excrements, seeds, and live prey) or food sizes (Torres 1984; Houadria et al. 2015). Additionally, species can show temporal activity patterns that allow them to avoid competitors (Torres 1984; Stuble et al. 2013; Houadria et al. 2016; Rosumek 2017). For instance, nocturnal species like some Myrmecia or Polyrhachis ants have adapted to low light levels by developing large eyes and efficient navigational strategies (Narendra et al. 2013a, 
b, 2017). On the other hand, activity patterns of tropical species are also dependent on moisture gradients (Kaspari and Weiser 2000).

Despite these mechanisms of niche differentiation, competition cannot be avoided entirely. The foraging strategies used by the different species are likely to have a strong impact on the ability of colonies to monopolize and exploit food sources fast and efficiently (Traniello 1987, 1989a; Lach et al. 2010; Drescher et al. 2011; Grevé et al. 2019). In particular, communication and recruiting other nestmates to food sources should increase a colony's chances of displacing competitors and gaining long-term access to food.

Communication among nestmates is widespread in ants and other social insects (Beckers et al. 1989; Hölldobler and Wilson 1990; Jarau and Hrncir 2009; Almeida et al. 2018; Glaser and Grüter 2018; Grüter and Czaczkes 2019). It allows the members of a colony to exchange information about their environment, such as the locations of food sources or the presence of predators and competitors (Kendal et al. 2004; Dawson and Chittka 2014; Lanan 2014). During communication, ants may use tactile signals (e.g. antennation, drumming or vibrations (Hölldobler 1999; Franklin 2014)) or chemical signals (e.g. alarm or trail pheromones (Hölldobler 1976, Traniello 1989b, Lach et al. 2010; Czaczkes et al. 2015)). Ant species with large colony sizes often use chemical mass-recruitment with short- or long-lasting trails, trunk trails, and mass-raids (Beckers et al. 1989, Traniello 1989a, Hölldobler and Wilson 1990, Lanan 2014; Czaczkes et al. 2015). Species with smaller colonies use recruitment strategies like tandem running or group recruitment (Möglich et al. 1974; Beckers et al. 1989; Liefke et al. 2001).

In tandem running, an informed ant returns to the nest after finding a good nest site or a rewarding food source that is too large to be exploited by a single ant. In the nest, she releases a pheromone to attract a potential recruit (Möglich et al. 1974). When the pair walks towards the resource, the follower antennates the leader's gaster and hind legs to maintain cohesion (Franklin 2014). Although ants in a tandem run-walk slower than ants walking alone, tandem recruitment could save time if resources are hard to find by independent search (Franks and Richardson 2006). Many species (e.g. in Temnothorax or Pachycondyla) use tandem running for both nest emigrations and foraging recruitment (Colin et al. 2017; Grüter et al. 2018), whereas others (e.g. Neoponera or Diacamma) perform tandem runs only during colony migrations, but not during foraging (Fresneau 1985; Kaur et al. 2017). This raises the question whether and how tandem running might improve foraging success and, in particular, whether tandem recruitment might improve foraging success when the competition is intense.
Tropical ants with small colony sizes might be particularly prone to direct competition, so-called interference competition, because they have to compete with mass-recruiting species that use pheromone trails to recruit large numbers of foragers and soldiers that are specialized to fight (Dejean et al. 2005; Czaczkes et al. 2011, 2015; Czaczkes and Ratnieks 2012). It seems highly plausible that communication helps mass-recruiting colonies to monopolize food sources, but it remains unclear whether this is also the case in species with small colonies that use slower forms of communication, such as tandem running. So far, only very few studies have assessed the role of communication in foraging competition in ants. One such study by Dejean et al. (2005) found that Pheidole megacephala (Fabricius, 1793) increases recruitment when they perceive competitors near food sources. Most ponerine ants live in small colonies (often just a couple of hundred individuals or less), they are important generalist arthropod predators and show a diversity of foraging strategies (Nascimento et al. 2012; Schmidt 2013), one of which is tandem recruitment (Grüter et al. 2018).

Here, we tested if recruitment communication helps colonies to be more successful in a highly competitive tropical environment. As a model system, we studied Pachycondyla harpax (Fabricius, 1804), a common Neotropical species that usually uses tandem running to recruit nestmates to newly discovered food sources (Grüter et al. 2018). A previous study observed that $P$. harpax foragers are often displaced at food sources by aggressive competitors, mainly Pheidole (Grüter et al. 2018). First, we described and quantified the main competitors of $P$. harpax in a Brazilian environment. Second, we tested our main prediction that tandem recruitment helps colonies to access food sources that would otherwise be monopolized by competitors. Third, we tested if $P$. harpax might follow a strategy of temporal and spatial niche differentiation to avoid competition, e.g. by foraging in locations and during times when competition for food is lower.

\section{Materials and methods}

\section{Study site and study species}

Experiments were performed in March 2018 and February/ March 2019 on the campus of the University of São Paulo in Ribeirão Preto, Brazil. Our study species Pachycondyla harpax forages for dead and living insects and plant seeds (Grüter et al. 2018). If scouts detect food items, they cannot carry home by themselves, e.g. beetle larvae or caterpillars, they often initiate tandem runs to recruit nestmates to the food source. This species is common in the study area and nests underground (Grüter et al. 2018). Colony 
sizes range from 15 to 100 individuals that aggressively defend food sources against many smaller ants (Wheeler 1900).

\section{Experimental setup and procedure}

All experiments were conducted in the field in three different locations on the campus, where P. harpax occurred. We located and marked colonies by following foragers who return to their nest after offering them small pieces of cheese (mozzarella or "queijo minas").

\section{Part 1: interspecific competition depending on food types, daytime and territory}

We first attempted to identify competitors of $P$. harpax and explored whether our focal species has a preference for different baits. We consider other ant species that forage at the same time and collect the same food type to be competitors. This does not imply aggressive interactions, i.e. interference competition since also non-aggressive species can reduce the foraging success of focal colonies via exploitation competition (Human and Gordon 1996; Lach 2005). Furthermore, we checked if $P$. harpax face different levels of competition at different food types and distances from the colony entrance. We tested 15 colonies with four different food sources: we used honey and pieces of mango (approx. $1 \mathrm{~cm}^{3}$ ) as carbohydrate baits and cheese cubes (approx. $1 \mathrm{~cm}^{3}$ ) or meat (pieces of sausage or mealworms) as protein-rich food sources. Food baits were placed at two different distances from the colony entrances: either at $30 \mathrm{~cm}$ ("inner territory") or at $100 \mathrm{~cm}$ ("outer territory"). Previous research has shown that most food items are collected $<100 \mathrm{~cm}$ from the nest entrance (Grüter et al. 2018).

Furthermore, we tested if $P$. harpax face stronger competition during the daytime or at night. We offered food baits (cubes of cheese, approx. $1 \mathrm{~cm}^{3}$ ) during the morning $(9.00-12.00 \mathrm{~h})$ and after sunset $(18.30-21.00 \mathrm{~h})$. Due to the low activity of $P$. harpax in the afternoon, we did not test for competition during that time. We again tested the influence of distance from the nest.

After providing a food source, we recorded the number of different ant species (competitors) at the food bait during and at the end of a 10-min observation period. In case an ant species could not be identified by the observer, specimens were collected for later identification. Ants were identified by comparison with the species of the Entomological Collection Padre Jesus Santiago Moure, Universidade Federal do Paraná, Curitiba, Brazil (DZUP), where the vouchers were deposited.

\section{Part 2: exploitation and recruitment depending on competition}

We provided food baits to 42 individual foragers of $P$. har$\operatorname{pax}$ (31 colonies). After they accepted the food and, thus, were the first species at the food source (treatment bait, without competition at the beginning), we provided a second food source as a control bait approx. $30 \mathrm{~cm}$ from the first food source and at a similar distance to the nest. The second food source was normally discovered quickly by competitors but could also be found by P. harpax. The second bait allowed us to perform a paired comparison between the two baits near a colony. As soon as the food sources were placed, we started filming (JVC GZ-GX1 camcorder) the immediate surroundings of the two food baits. In some trials, we made still images of the control bait. We recorded at least one image per minute. Additionally, both baits were regularly inspected. Each trial was filmed for approx. $60 \mathrm{~min}$. Observations ended earlier if other ant species displaced $P$. harpax from the first bait. It was not possible to quantify the number of food that was removed from the bait without disturbing the experiments. We frequently observed single foragers, to breaking-off bits and to walk away and transporting it back to the nest.

During video analysis, we recorded the distance of each bait from the nest (whenever possible), the probability of recruitment by $P$. harpax colonies, the maximum number of $P$. harpax foragers at the bait (at the same time), whether and for how long P. harpax foragers had access to the bait, the time until competitors found the bait and if there was a takeover (within 60 min after initial discovery P. harpax did not have access anymore) by competitors. $P$. harpax foragers were considered to have access to the food source (yes or no) when the individuals of a colony had access to the food source for at least $15 \mathrm{~min}$ and were able to collect and exploit the food bait, even if there were other non-aggressive ant species present. We considered a takeover by another ant species to have occurred when $P$. harpax could no longer feed at the bait.

\section{Part 3: daily activity of Pachycondyla harpax}

We observed that $P$. harpax appeared to be more active after sunset (unpublished data; see also García-Pérez et al. 1997). To confirm this, we observed 15 colonies at various locations on the campus during several days (14 March 2019-21 March 2019), from $9.30 \mathrm{~h}$ in the morning until $20.00 \mathrm{~h}$ in the evening. Each colony was observed for one minute and all $P$. harpax individuals in an area of one meter around the nest entrance were recorded. If we found no focal ant, the colony was considered to be inactive. After sunset, we explored the surrounding of the nest entrance using the light of headlamps. 


\section{Part 4: food exploitation success depending on daytime}

To compare the foraging success of $P$. harpax during the daytime (9.30-12.00 h) and after sunset (18.30-21.00 h), we tested 15 colonies in both time periods and provided cheese baits for individual $P$. harpax foragers. Every five minutes during a 45-min observation period we performed a scan-sampling and checked whether foragers from the focal colony still had access and recorded the maximum number of foragers that were simultaneously present at the food source. This allowed us to explore the competitive performance of colonies during the day and at night.

\section{Statistical analysis}

All tests were performed in R 3.5.3 (R Development Core Team 2019). We performed linear mixed-effect models (LMEs) for normally distributed response variables and generalized linear mixed-effect models (GLMMs) for response variables with a binomial or Poisson distribution (Zuur et al. 2009). For the competition and food exploitation experiments, colony ID was used as a random effect to account for the potential non-independence of observations from the same colony. Location was used as a random factor for the recruitment experiments (Zuur et al. 2009). For the activity analyzes, we used colony and date as random factors. In part 1, we tested the role of the fixed effects "daytime", "colony territory" (inner vs. outer) and "food type" on the presence of competitors and $P$. harpax activity. In part 2, to test the influence of recruitment on the foraging success, we used the fixed effects "maximum number of $P$. harpax foragers at the baits" and "recruitment" (yes or no) to test if they predicted whether $P$. harpax had access (yes or no) to the food bait. Since these predictors are linked, we explored their importance separately. With a McNemar's test we analyzed if the probability to recruit was higher at the treatment than at the control feeder. To test for significant interactions among the fixed-effects, we used likelihood ratio tests (LRT) and compared the model without the interaction with the model containing the interaction. Non-significant interactions were removed from the model. In part 3, we tested if colony activity (ants vs. no ants) depended on the time of the day. In part 4, we quantified the foraging activity of focal colonies depending on the time interval during the 45-min observation period.

\section{Results}

\section{Interspecific competition depending on food types and territory}

Overall, we identified almost 40 different ant species at our baits during the 10-min observation periods (Table 1). The most common competitors of $P$. harpax were mass-recruiting Pheidole species (mostly Pheidole oxyops Forel 1908), Odontomachus sp.; rarely, we found Atta or Camponotus at a food bait (Fig. 1). A similar number of ant species

Table 1 Competing ant species observed at different food baits during our observations

\begin{tabular}{|c|c|}
\hline Subfamily & Species \\
\hline Dolichoderinae & $\begin{array}{l}\text { Dolichoderus bispinosus } \\
\text { Linepithema gallardoi }\end{array}$ \\
\hline Formicinae & $\begin{array}{l}\text { Brachymyrmex sp. } \\
\text { Camponotus (Myrmaphaenus) sp. } 1 \\
\text { Camponotus (Myrmaphaenus) sp. } 2 \\
\text { Camponotus ager } \\
\text { Camponotus atriceps } \\
\text { Camponotus substitutus } \\
\text { Sericomyrmex mayri }\end{array}$ \\
\hline Myrmicinae & $\begin{array}{l}\text { Acromyrmex sp. } \\
\text { Apterostigma gr. pilosum } \\
\text { Atta sexdens } \\
\text { Crematogaster erecta } \\
\text { Nesomyrmex sp. } \\
\text { Pheidole angusta } \\
\text { Pheidole gertrudae } \\
\text { Pheidole oxyops } \\
\text { Pheidole sensitiva } \\
\text { Pheidole sp. } 1 \\
\text { Pheidole sp. } 2 \\
\text { Pheidole sp. } 3 \\
\text { Pheidole sp. } 4 \\
\text { Pheidole aff radoszkowskii sp. } 1 \\
\text { Pheidole aff radoszkowskii sp. } 2 \\
\text { Pheidole aff subarmata } \\
\text { Solenopsis decipiens } \\
\text { Solenopsis sp. } \\
\text { Mycetomoellerius sp. } \\
\text { Wasmannia auropunctata }\end{array}$ \\
\hline Ponerinae & $\begin{array}{l}\text { Hypoponera sp. } \\
\text { Neoponera verenae } \\
\text { Neoponera villosa } \\
\text { Odontomachus chelifer } \\
\text { Odontomachus sp. } \\
\text { Pachycondyla striata }\end{array}$ \\
\hline
\end{tabular}



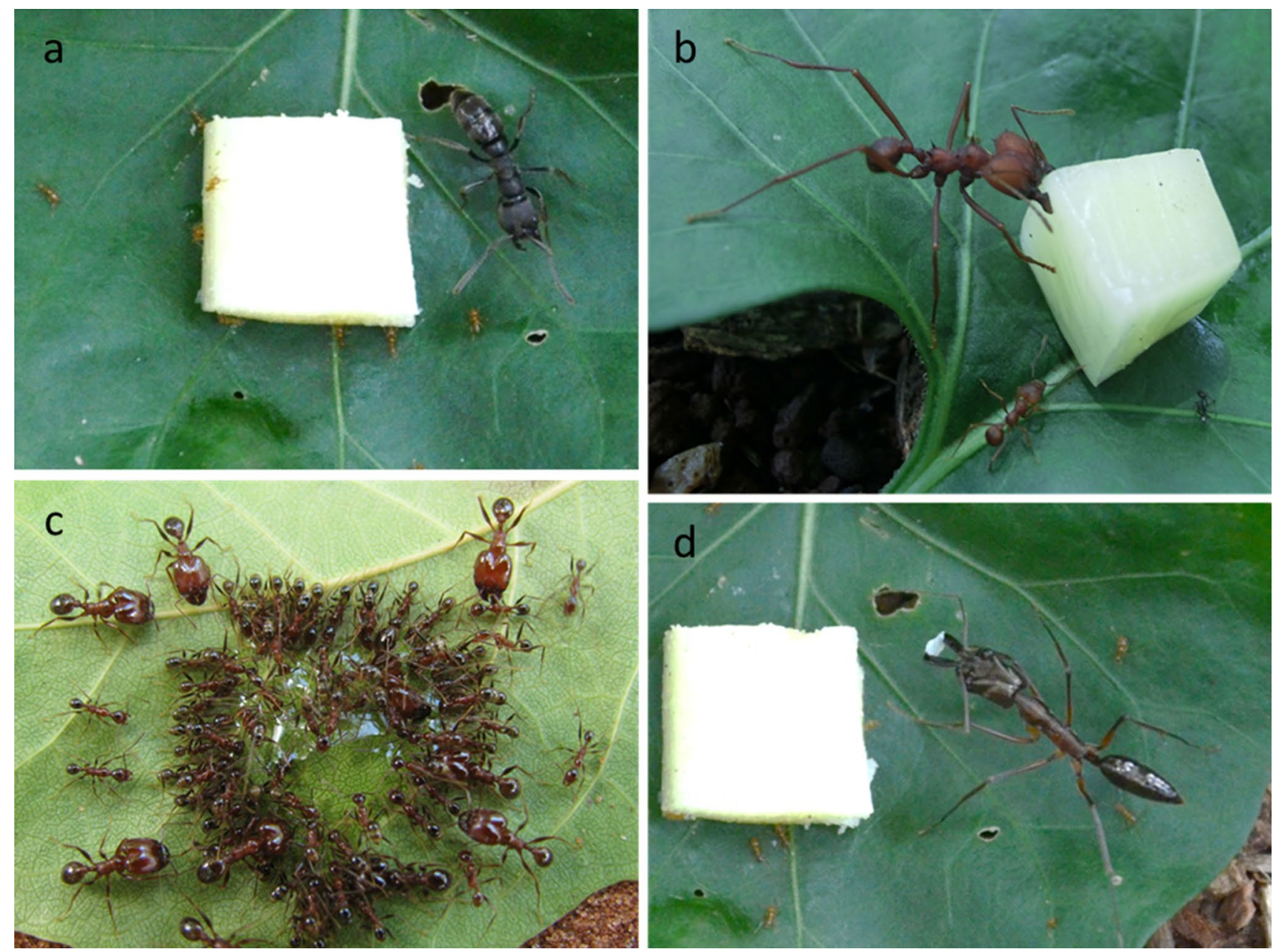

Fig. 1 Study species and competitors at food baits. a Pachycondyla harpax defending the food source against Wasmannia auropunctata. b Atta sexdens picking up and carrying away the cheese bait. c Work-

discovered the different types of food during the 10-min observation period, irrespective of the distance from the $P$. harpax focal colony (range $=30-100 \mathrm{~cm}, 2.68 \pm 1.20$ species $[$ mean $\pm \mathrm{sd}])$. There was a borderline significant difference between the total number of species that discovered honey compared to meat, with more species collecting honey than meat (GLMER: inner vs. outer territory: $z=-0.792, p=0.428$; food sources: meat vs. honey: $z=2.080, p=0.038$; meat vs fruit: $z=0.816, p=0.415$; meat vs. cheese: $z=0.931, p=0.352$; cheese vs. honey: $z=1.190$, $p=0.234$; cheese vs. fruit: $z=-0.095, p=0.924$; fruit vs. honey: $z=1.252, p=0.211$ ). At the end of the 10 -min observation period, the number of ant species at the food baits decreased to $1.36 \pm 0.76$ species and there was no difference between food types (GLMER: inner vs. outer territory: $z=-0.643, p=0.520$; food sources: meat vs honey: $z=1.500, p=0.134$; meat vs fruit: $z=-0.067, \mathrm{p}=0.947$; meat vs. cheese: $z=0.420, p=0.675$; cheese vs. honey: ers and soldiers of mass recruiting Pheidole oxyops (Photo by Tomer Czaczkes). d Odontomachus chelifer carrying away a small piece of cheese

$z=1.104, p=0.269$; cheese vs. fruit: $z=-0.479, p=0.125$; fruit vs. honey: $z=1.536, p=0.211$ ). This reduction is likely due to the displacement of weakly competitive species by competitively superior species.

\section{Exploitation and recruitment depending on competition}

We found that after offering $P$. harpax foragers a bait, a substantial proportion of ants initiated tandem recruitment. In $42.9 \%$ (18 out of 42 ) of all trials, at least one forager started recruiting. The control bait was found in $38.1 \%$ (16 out of 42 ) of all trials by at least one $P$. harpax forager. Tandem recruitment to the control bait occurred in $37.5 \%$ (6 out of 16) of these trials (14.3\% of all trials). Overall, tandem recruitment by $P$. harpax foragers was significantly more likely at the treatment bait than at the control bait (McNemar's test: $\left.\chi^{2}=6.050, d f=1, p=0.014\right)$. The distance between the nest 
and the food source did not influence recruitment probability (GLMER: $z=1.052, p=0.293$ ). When comparing the number of $P$. harpax foragers at the two baits, we found no correlation between the maximum number of ants at the treatment and control feeder (GLMER: $z=-0.653, p=0.514$ ). A positive correlation might have been expected if the number of ants at the two paired baits would have been the result of the colony size of the focal colony or reflected the level of competition in the area of the focal colony. Furthermore, competitors found the treatment and control feeder equally fast (treatment: $1.66 \pm 2.28 \mathrm{~min}$ vs. control: $2.05 \pm 1.79 \mathrm{~min}$ (mean \pm sd); GLMER: $z=-1.318, p=0.187$ ) and there was no correlation of time of discovery by competitors (GLMER: $z=1.526, p=0.127)$.

We predicted that recruitment would lead to an increase in ants at the bait and, in turn, a higher probability to have access to the food bait. The results show that significantly more ants reached the food source when recruitment took place (Fig. 2a) (GLMER: $z=5.942, p<0.001$ ). Thus, when ants performed more tandem runs, the maximum number of ants that were present at a bait increased (GLMER: $z=4.486, p<0.001$ ). During a trial, individual foragers were often seen walking to the nest with small pieces of food and, subsequently, return to the food source in a tandem run or alone. We found that recruitment was associated with a more than 4-times higher probability to have access to the food source (no recruitment: $20.8 \%$ vs. recruitment: 88.9\%) (Fig. 2b) (GLMER: $z=2.723, p=0.006$ ). Related to these two findings, we predicted that colonies are more likely to keep access if more ants are at the food source. We found that the probability of having access increased significantly with an increasing number of foragers at the food bait (Fig. 2c) (GLMER: $z=2.723, p=0.006)$ : $P$. harpax colonies had a $100 \%$ access chance when at least three ants were at the food source.

When competitors took over the food source at any time during the 60-min observation period, $P$. harpax stopped recruiting. We tested if an increasing number of foragers at the food source lowered the chance of a takeover by another species and indeed found this to be the case (GLMER: $z=-3.087, p=0.002$ ). When there were at least five ants of $P$. harpax at the food bait, takeover was extremely unlikely (Fig. 2d).

\section{Activity cycle}

We found in the first experiments that $P$. harpax has an increased activity after sunset $(\sim 6.30 \mathrm{pm}$ ) (see also García-Pérez et al. 1997). Therefore, we quantified the activity of 15 colonies from early morning (sunrise $\sim 6.15$ am) until after sunset $(9: 30 \mathrm{~h}$ to $20: 00 \mathrm{~h}$ ) over eight days (Fig. 3). There was substantial variation in activity throughout the day. As described by García-Pérez et al.
(1997) in a different area, activity was generally low during the day and increased in the evening around $17.00 \mathrm{~h}$ up to 18.30 h (GLMER: $\chi^{2}=84.133, d f=7, p<0.001$ ). While observing the colony activity, we also measured the temperature throughout the day. The morning counts ended around 11 am $\left(26.88{ }^{\circ} \mathrm{C} \pm 1.63{ }^{\circ} \mathrm{C}\right)$. The afternoon counts lasted from $12: 30 \mathrm{pm}$ until $5 \mathrm{pm}\left(28.70{ }^{\circ} \mathrm{C} \pm 1.72{ }^{\circ} \mathrm{C}\right)$. Sunset was typically around $6: 30 \mathrm{pm}$. This is when our evening measurements started $\left(24.70{ }^{\circ} \mathrm{C} \pm 1.34{ }^{\circ} \mathrm{C}\right)$. The temperature was always measured a few $\mathrm{cm}$ above the ground in shaded areas.

\section{Interspecific competition depending on daytime and territory}

One explanation for the increased activity at night could be that colonies face less competition than during the daytime. Thus, we compared the number of ant species at food baits in the morning vs. the evening. Contrary to our expectation, we observed that significantly more competitor species discovered the bait after sunset (Fig. 4a) (LME: $t=-2.355$, $p=0.024)$. There was also a tendency for more ant species to discover the bait closer to the nest entrance (LME: $t=-1.753, p=0.087$ ).

The probability that $P$. harpax foragers would discover the baits during the 10-min observation period was higher at night than during daytime (Fig. 4b) (GLMER: $z=-2.332$, $p=0.020$ ). This probability did not depend on the distance of the cheese bait from the nest entrance of the focal colonies (GLMER: $z=-0.354, p=0.724$ ). There was a borderline non-significant trend that $P$. harpax were more likely to still have access to the food at night compared to daytime at the end of the 10-min observation period, (GLMER: daytime: $z=1.910, p=0.056$; territory: $z=-0.363, p=0.716)$. The most frequent and successful competitor was the massrecruiting Pheidole oxyops (present in $62.2 \%$ experiments) (Fig. 1c).

\section{Food exploitation and access depending on daytime}

We then presented individual $P$. harpax foragers with cheese baits to explore whether time of day affected their ability to maintain access to the food source during a 45-min observation period. During daytime, the number of foragers at the bait remained constant and low, whereas the number of $P$. harpax at the food increased after sunset (Fig. 5a, b) (GLMER: morning vs. evening: $z=-8.056, p<0.001$; time: morning: $\chi^{2}=10.033, d f=8, p=0.263$; evening: $\chi^{2}=27.66$, $d f=8, p<0.001)$.

Not all colonies were able to keep access to the food bait over the $45 \mathrm{~min}$. After sunset, more colonies kept access to the food source than in the morning (morning: $18.5 \%$ vs. 
a

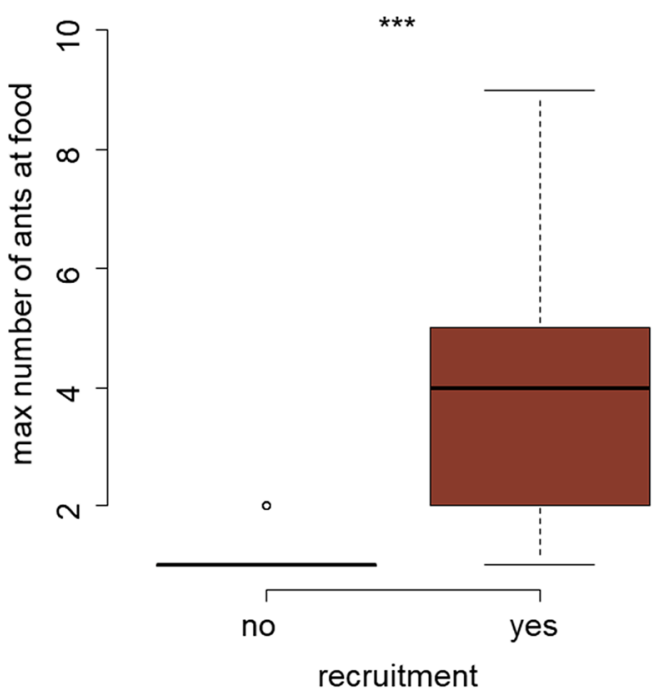

C

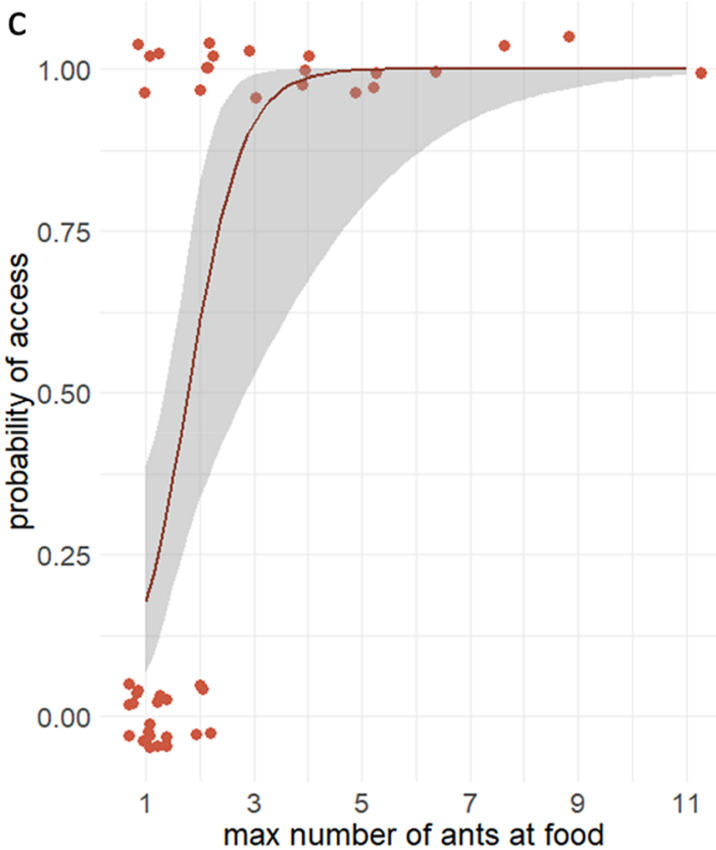

Fig. 2 Maximum number of ants (a) and the probability of ants at the food source (b) depending on whether our focal colony performed tandem recruitment. Probability of access (c) and of a food takeover by a competitive ant species (d) depending on the maximum number of ants at the food source. Access refers to a period of exploitation of at least 15 min during the observation period. Takeovers occurred

evening: 58.6\%) (Fig. 5c, 5d (GLMER: morning vs. evening: $z=-8.056, p<0.001$; time: morning: $\chi^{2}=3.2 \times 10^{10}, d f=8$, $p<0.001$; evening: $\chi^{2}=801.82, d f=8, p<0.001$ ).
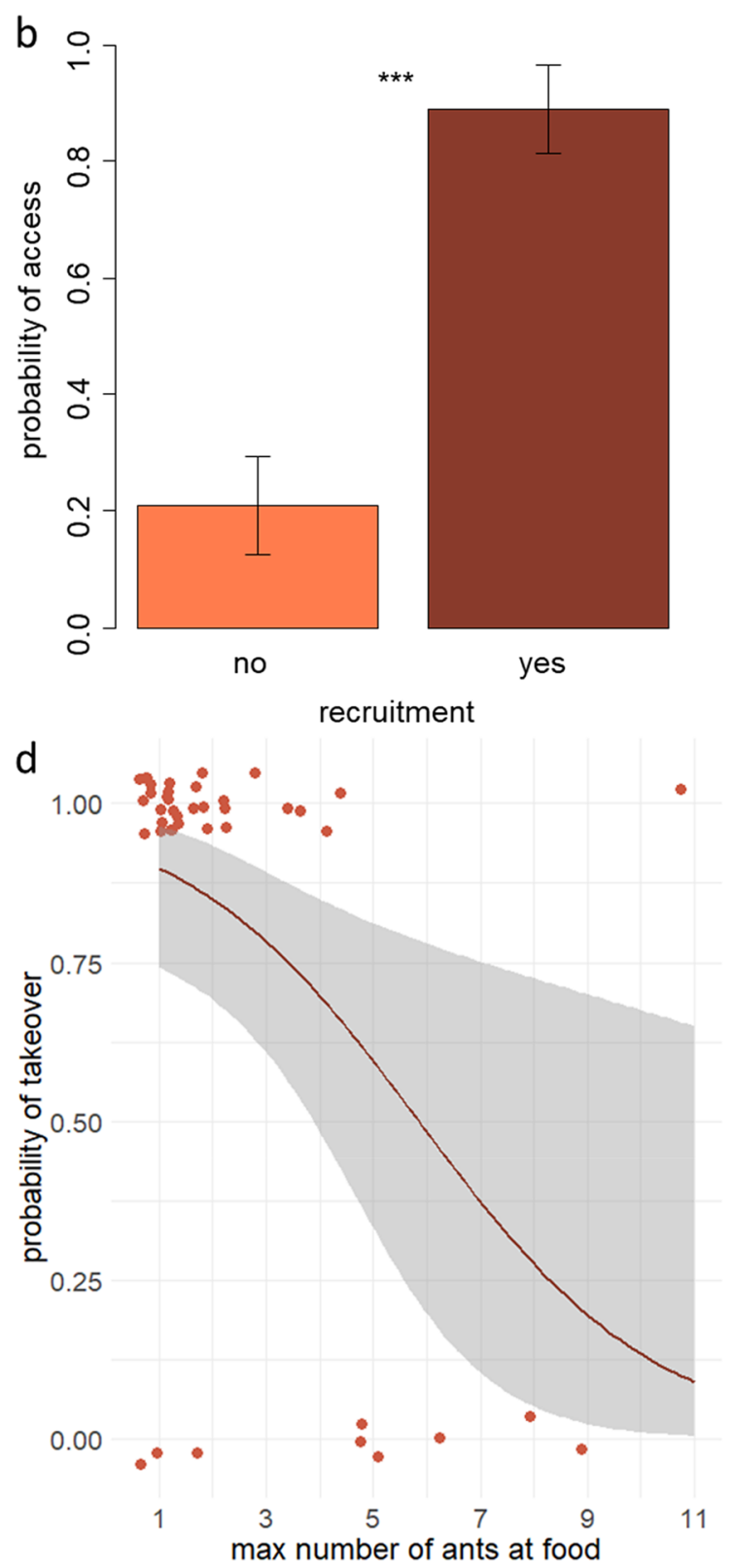

when focal colonies were displaced during the 60 min observation period. Boxplots show median, 25th and 75th quartile and the 5th and 95th percentile. Bar plots show means and SE. Note that all values in (c) and (d) are either 1 or 0 but that jitter was used to better visualize the data points. Grey areas show the $95 \%$ confidence interval. $* * * p<0.001$

\section{Discussion}

Our results support the hypothesis that recruitment communication by tandem running increases access to food sources and, thus, foraging success in Pachycondyla harpax. Competition in this Brazilian habitat was intense for all types of food as almost 40 different ant species discovered and exploited our baits during our observations. This 
Fig. 3 The probability of colony activity of $P$. harpax foragers during daytime over 8 days $(n=15)$. Sunset was around 18.30

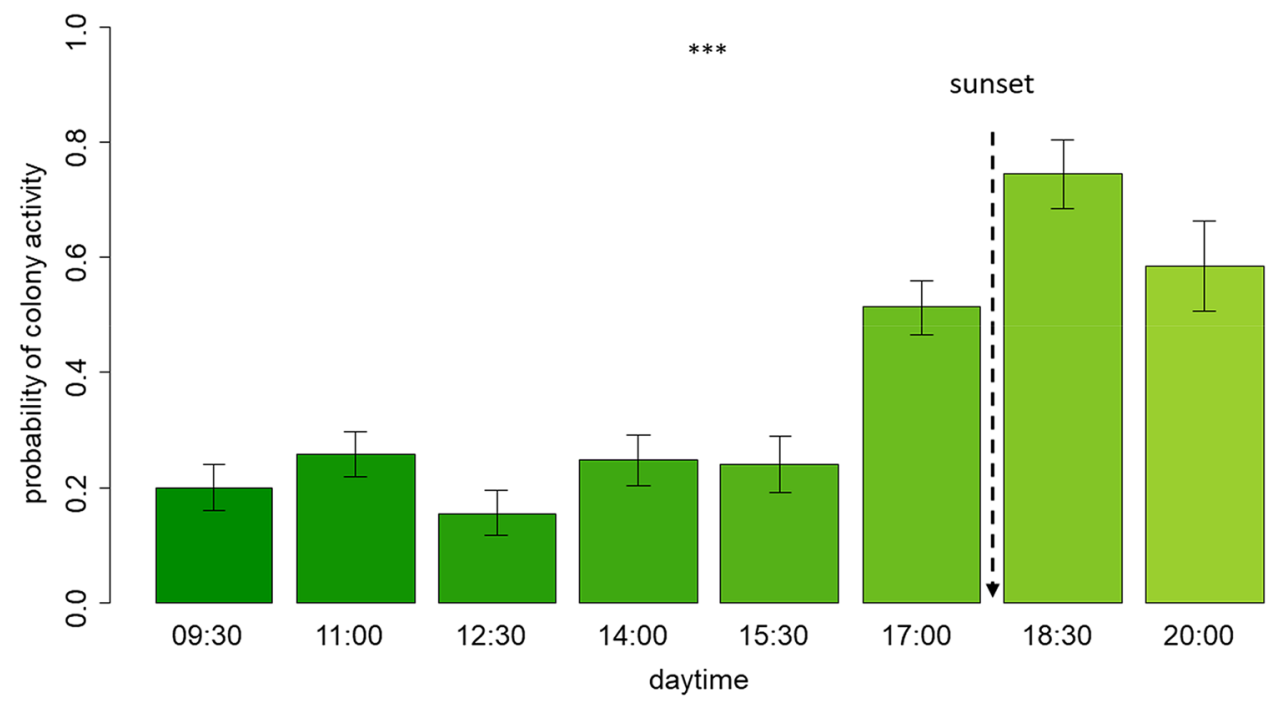

a

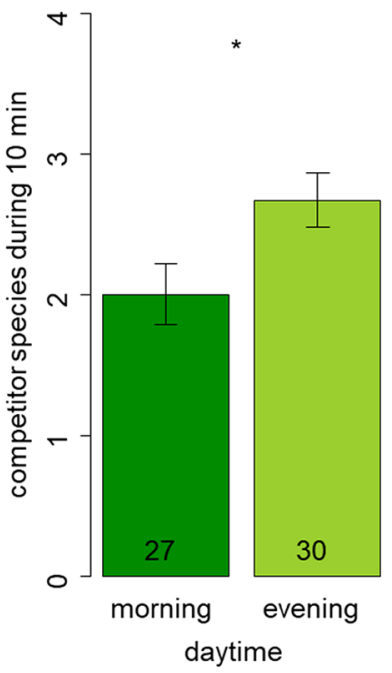

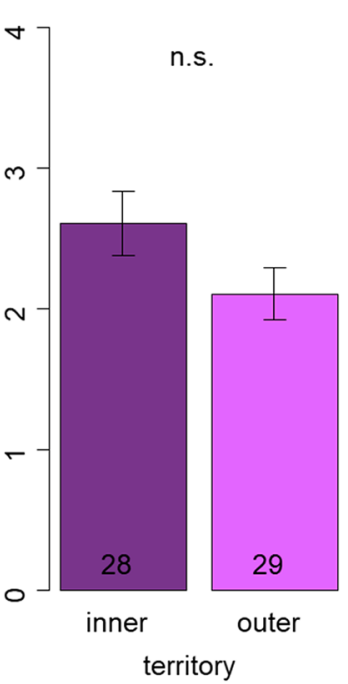

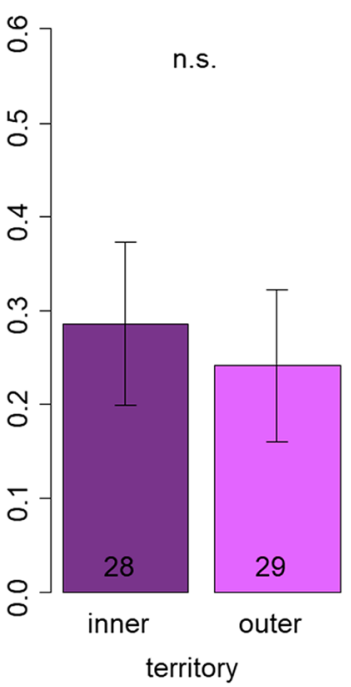

Fig. 4 Number of different competitors (a) and the probability (b) that $P$. harpax would discover the bait during 10 min depending on the time of day and the distance from the entrance of the focal colony (territory). Sample sizes refer to the number of trials. n.s. not significant, ${ }^{*} p<0.05$

intense competition is not surprising given that $P$. harpax is a generalist forager, like many other Neotropical ant species. Confronted with big food items, foragers attempted to cut off small pieces of food and transport them back to the nest. However, they were frequently displaced by competitor species. Although several different species can discover a food source, only a few of them remain at the food bait over longer time periods. This reduction is likely due to displacement by competitively superior species. The most abundant competitors were Pheidole spp. (Table 1; 94.6\% of all observations), which are very efficient and aggressive mass-recruiters (Czaczkes et al. 2011; Czaczkes and Ratnieks 2012). While it was not possible to collect data on the number of competing individuals at baits, the observations on the dominance of Pheidole spp. suggest that the number of competing ants affects the ability of $P$. harpax to access and defend food items. In some cases, however, a single individual of Odontomachus or Neoponera could banish their competitors, demonstrating that there is not always a straightforward relationship between the number and dominance of competitors. Different competitors could also fight against each other and thereby give a third party the opportunity to have access and exploit a food bait.

It is often assumed that mass-recruitment via pheromone trails helps colonies to monopolize food sources (de Biseau et al. 1997; Detrain and Deneubourg 2008; Drescher et al. 2011). Accordingly, Pheidole megacephala scouts start recruiting more nestmates and soldiers to a food source 

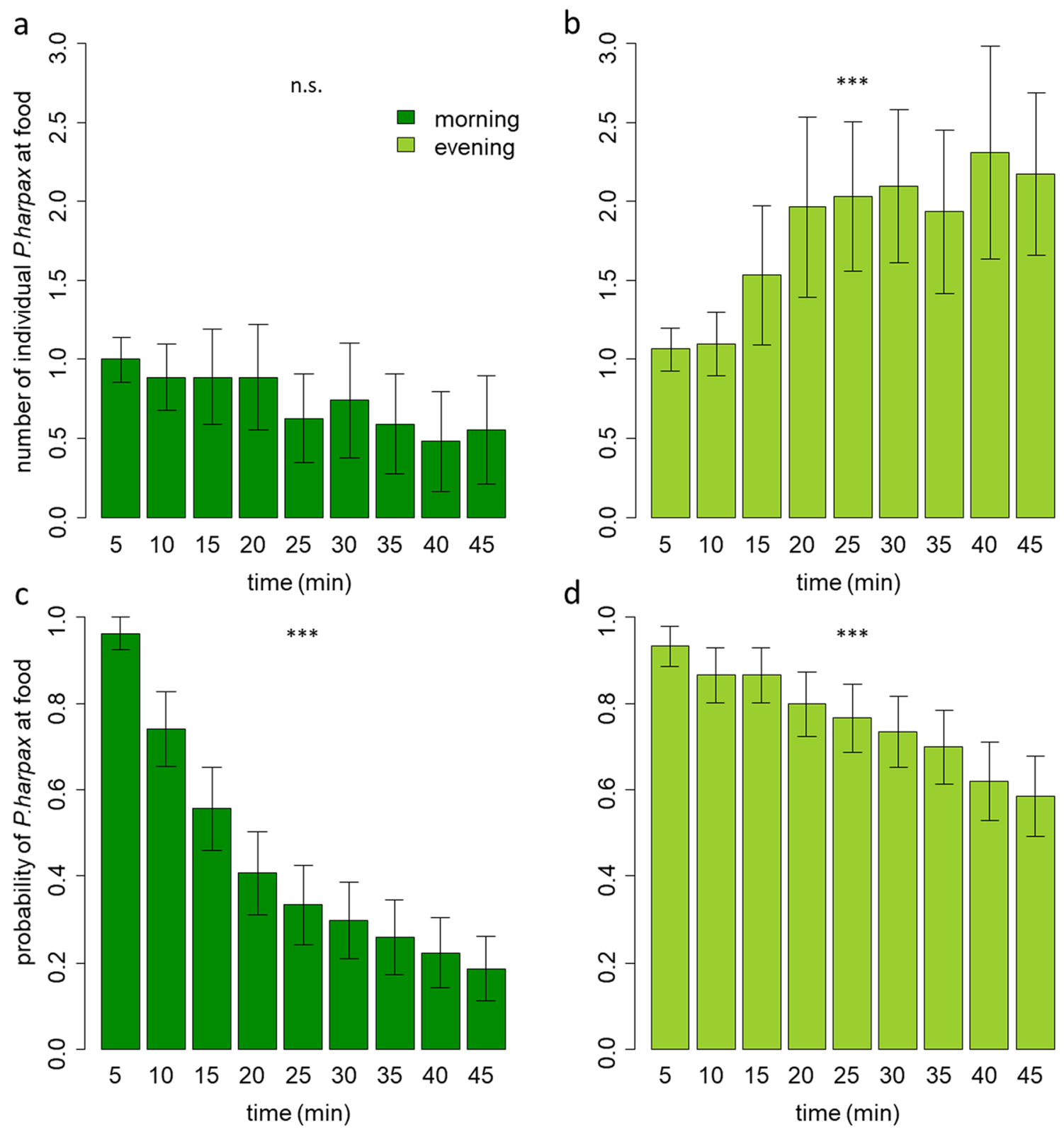

Fig. 5 Number of individual P. harpax workers and the probability of colony presence at food baits during the 45-min period in the morning (a, c) and evening (b, d). n.s. not significant, $* * * p<0.001$

if pheromones from competing colonies are encountered (Dejean et al. 2005). Our results support and extend this view by showing that also species with small colonies employing relatively slow recruitment mechanisms are likely to benefit from recruitment communication. When $P$. harpax foragers had an opportunity to recruit nestmates to a food source, their foraging success was much higher: focal colonies with recruitment were 4 times more likely to keep access to the food during our observations. This is likely to allow more foragers to recruit further ants, leading to positive feedback and a larger number of ants at the food. The bait was unlikely to be taken over by competitors when about five or more $P$. harpax foragers were at the food source (Fig. 2d). When P. harpax foragers found the food source by chance, they were often not able to exploit it for longer time periods if competitors were already present and prevented other $P$. harpax ants to recruit nestmates. When focal foragers discovered the bait before competitor species, as was the case at the treatment bait, tandem recruitment was much more frequently observed compared to the control bait (43\% vs. $14 \%$ ), which was randomly placed in the vicinity of the same nest. Thus, finding a food source first, before competitor species, is of critical importance to foraging success. The recruitment probability in $P$. harpax is comparable or higher 
than in other species that use recruitment methods other than chemical trails. For example, about $10 \%$ of returning honeybee foragers perform a waggle dance (Seeley 1995) and $\sim 10$ to $30 \%$ of ant foragers lead tandem runs to food sources in Cardiocondyla venustula and Temnothorax nylanderi (Wilson 1959; Glaser and Grüter 2018).

Competition might be less intense in some areas, allowing more $P$. harpax foragers to have access for longer and to recruit nestmates to exploit the food source. A large number of $P$. harpax at a bait might also indicate a large colony size. In both cases, we would expect a positive correlation between the paired treatment and control baits in terms of the number of $P$. harpax foragers exploiting them. In other words, the two baits in the proximity of a particular nest should be similar in the number of $P$. harpax foragers. However, this was not the case in our study as the number of $P$. harpax foragers at the treatment feeder was unrelated to the number at the paired control feeder. Additionally, there was no correlation in how quickly competitors found the treatment and control feeder. This finding, in combination with our other findings, suggests that the number of ants at a bait is largely the result of discovering a food source first, followed by successful recruitment. Colony size might still be an important factor for competitiveness. When a colony is larger, more individuals can scout or be recruited to a food source. Hence, larger colonies are probably more successful during foraging compared to smaller colonies (Dornhaus et al. 2012). In addition, foragers from larger colonies might also be more aggressive (Oster and Wilson 1978), which would further affect access to food sources.

One possibility to avoid competition might be to forage during different times of the day, as is the case with nocturnal and diurnal species (Rosumek 2017). In a study on grassland ants, for example, different species foraged at different times of the day depending on air temperature (Albrecht and Gotelli 2001). This temporal niche partitioning can help subdominant species to avoid dominant species (Stuble et al. 2013). Stingless bees, likewise, shift their activity to avoid the presence of other, mainly aggressive species (Nagamitsu and Inoue 1997, Keppner and Jarau 2016). In the tropics, species also can adapt to different seasons, e.g. by being more active during the rainy seasons (Baumgartner and Roubik 1989), whereas others are active during both seasons. In accordance with a previous study (García-Pérez et al. 1997), we observed that the activity of $P$. harpax increases in the afternoon and is highest after sunset. Thus, we hypothesized that this shift in activity is due to the competition being less intense after sunset. Contrary to this expectation we found that competition seemed to be even stronger after sunset than during the morning/daytime: we found a $33 \%$ increase in the number of competitor species at the food baits after sunset. A possible explanation might be that most ant species start becoming more active when temperatures are going down and humidity increases to prevent water loss (Schilman et al. 2007). The $>100 \%$ increase in $P$. harpax activity after sunset (Fig. 3) more than compensated for the increase in competitor species after sunset (Fig. 4) and, as a result, $P$. harpax colonies were better able to defend and exploit food sources after sunset (Fig. 5). After 45 min, only $18.5 \%$ of the colonies maintained access to the food during the morning compared to $56.6 \%$ after sunset. This suggests that $P$. harpax might be more successful during the night because they increase their activity at a higher rate than other ant species. As a result, we observed an increase in the number of foragers at the food bait over time after sunset, but not during daytime. This increase is most likely due to ants being recruited via tandem runs (personal observation) in combination with a higher rate of independent discoveries at night.

\section{Conclusions}

It is often assumed that recruitment communication in social insects is beneficial for foraging success (but see DechaumeMoncharmont et al. 2005, I'Anson Price et al. 2019). One key benefit could be that recruitment allows colonies to monopolize food sources in a competitive environment by building up a critical mass of nestmates to defend a large resource. However, evidence for this has been scarce. In our study, we show that Pachycondyla harpax is likely to improve their foraging success thanks to tandem recruitment. The results also indicate that foragers have better access to food sources at night, most likely aided by recruiting nestmates. This highlights the potential influence of communication on foraging success and efficiency in ants, including those species with small colony sizes and slow, direct recruitment communication.

Supplementary Information The online version contains supplementary material available at https://doi.org/10.1007/s00040-021-00810-y.

Acknowledgements We thank the Department of Behavioural Ecology and Social Evolution, Johannes Gutenberg-University Mainz for feedback and advice.

Author contributions SMG and CG designed the experiments; RMF identified ant species; SMG, AK, NG, and CG performed experiments. SMG analyzed the data and wrote the primarily manuscript. All authors contributed critically to the drafts and gave final approval for publication.

Funding Open Access funding enabled and organized by Projekt DEAL. C.G. and S.G. were funded by the German Research Foundation (DFG: GR 4986/1-1). N.G. was partly funded by the FeldbauschStiftung. R.M.F. was supported by the Conselho Nacional de Desenvolvimento Científico (Grant 302462/2016-3). F.S.N. was funded by a 
Fapesp grant (2019/01148-8). Collection permits were obtained prior to field collection (Sisbio-ICMBio 26649).

Data availability statement Data deposited in the supplement.

\section{Compliance with ethical standards}

Conflict of interest The authors declare that they have no conflict of interest.

Ethical approval All applicable institutional and/or national guidelines for the care and use of animals were followed.

Open Access This article is licensed under a Creative Commons Attribution 4.0 International License, which permits use, sharing, adaptation, distribution and reproduction in any medium or format, as long as you give appropriate credit to the original author(s) and the source, provide a link to the Creative Commons licence, and indicate if changes were made. The images or other third party material in this article are included in the article's Creative Commons licence, unless indicated otherwise in a credit line to the material. If material is not included in the article's Creative Commons licence and your intended use is not permitted by statutory regulation or exceeds the permitted use, you will need to obtain permission directly from the copyright holder. To view a copy of this licence, visit http://creativecommons.org/licenses/by/4.0/.

\section{References}

Albrecht AM, Gotelli NJ (2001) Spatial and temporal niche partitioning in grassland ants. Oecologia 126:134-141

Almeida CS, Cristaldo PF, Desouza O et al (2018) Resource density regulates the foraging investment in higher termite species. Ecol Entomol 43:371-378. https://doi.org/10.1111/een.12508

Bar-On YM, Phillips R, Milo R (2018) The biomass distribution on earth. PNAS. https://doi.org/10.1073/pnas.1711842115

Baumgartner DL, Roubik DW (1989) Ecology of necrophilous and filth-gathering stingless bees (Apidae: Meliponinae) of Peru. J Kansas Entomol Soc 62:11-22

Beckers R, Goss S, Deneubourg JL, Pasteels JM (1989) Colony size, communication and ant foraging strategy. Psyche A J Entomol 96:239-256. https://doi.org/10.1155/1989/94279

Colin T, Doums C, Péronnet R, Molet M (2017) Decreasing worker size diversity does not affect colony performance during laboratory challenges in the ant Temnothorax nylanderi. Behav Ecol Sociobiol. https://doi.org/10.1007/s00265-017-2322-4

Czaczkes TJ, Ratnieks FLW (2012) Pheromone trails in the Brazilian ant Pheidole oxyops: extreme properties and dual recruitment action. Behav Ecol Sociobiol. https://doi.org/10.1007/s0026 5-012-1367-7

Czaczkes TJ, Nouvellet P, Ratnieks FLW (2011) Cooperative food transport in the neotropical ant, Pheidole oxyops. Insectes Soc 58:153-161. https://doi.org/10.1007/s00040-010-0130-1

Czaczkes TJ, Grüter C, Ratnieks FLW (2015) Trail pheromones: an integrative view of their role in social insect colony organization. Annu Rev Entomol 60:581-599. https://doi.org/10.1146/ annurev-ento-010814-020627

Davidson DW, Cook SC, Snelling RR, Chua TH (2003) Explaining the abundance of ants in lowland tropical rainforest canopies. Science (80-) 300:969-973

Dawson EH, Chittka L (2014) Bumblebees (Bombus terrestris) use social information as an indicator of safety in dangerous environments. Proc R Soc B Biol Sci. https://doi.org/10.1098/ rspb.2013.3174

de Biseau JC, Quinet Y, Deffernez L, Pasteels JM (1997) Explosive food recruitment as a competitive strategy in the ant Myrmica sabuleti (Hymenoptera, Formicidae). Insectes Soc 44:59-73. https://doi.org/10.1007/s000400050023

Dechaume-Moncharmont FX, Dornhaus A, Houston AI et al (2005) The hidden cost of information in collective foraging. Proc R Soc B Biol Sci 272:1689-1695. https://doi.org/10.1098/ rspb.2005.3137

Dejean A, Le Breton J, Suzzoni JP et al (2005) Influence of interspecific competition on the recruitment behavior and liquid food transport in the tramp ant species Pheidole megacephala. Naturwissenschaften 92:324-327. https://doi.org/10.1007/s0011 4-005-0632-2

Detrain C, Deneubourg J-L (2008) Collective decision-making and foraging patterns in ants and honeybees. Adv In Insect Phys 35:123-173

Dornhaus A, Powell S, Bengston S (2012) Group size and its effects on collective organization. Annu Rev Entomol 57:123-141. https ://doi.org/10.1146/annurev-ento-120710-100604

Drescher J, Feldhaar H, Blüthgen N (2011) Interspecific aggression and resource monopolization of the invasive ant Anoplolepis gracilipes in Malaysian Borneo. Biotropica 43:93-99

Franklin EL (2014) The journey of tandem running: the twists, turns and what we have learned. Insectes Soc 61:1-8. https://doi. org/10.1007/s00040-013-0325-3

Franks NR, Richardson T (2006) Teaching in tandem-running ants. Nature 439:153. https://doi.org/10.1038/439153a

Fresneau D (1985) Individual foraging and path fidelity in a ponerine ant. Insectes Soc 32:109-116. https://doi.org/10.1007/BF022 24226

García-Pérez JA, Blanco-Piñón A, Mercado-Hernández R, Badii M (1997) El comportamiento depredador de Pachycondyla harpax Fabr. sobre Gnathamitermes tubiformans Buckley en condiciones de cautiverio. Southwest Entomol 22:345-355

Glaser SM, Grüter C (2018) Ants (Temnothorax nylanderi) adjust tandem running when food source distance exposes them to greater risks. Behav Ecol Sociobiol 72:1-8. https://doi.org/10.1007/s0026 5-018-2453-2

Grevé ME, Houadria M, Andersen AN, Menzel F (2019) Niche differentiation in rainforest ant communities across three continents. Ecolony Evol 9:8601-8615. https://doi.org/10.1002/ece3.5394

Grüter C, Czaczkes TJ (2019) Communication in social insects and how it is shaped by individual experience. Anim Behav 151:207215. https://doi.org/10.1016/j.anbehav.2019.01.027

Grüter C, Wüst M, Cipriano AP, Nascimento FS (2018) Tandem recruitment and foraging in the ponerine ant Pachycondyla harpax (Fabricius). Neotrop Entomol 47:742-749. https://doi. org/10.5194/hess-16-3075-2012

Hölldobler B (1976) Tournaments and slavery in a desert ant. Science (80-) 192:912-914

Hölldobler B (1981) Foraging and spatiotemporal territories in the honey ant Myrmecocystus mimicus Wheeler (Hymenoptera: Formicidae). Behav Ecol Sociobiol 9:301-314. https://doi. org/10.1007/BF00299887

Hölldobler B (1999) Multimodal signals in ant communication. J Comp Physiol A 184:129-141

Hölldobler B, Wilson EO (1990) The ants. Harvard University Press, Springer, Berlin, Heidelberg

Houadria M, Salas-Lopez A, Orivel J et al (2015) Dietary and temporal niche differentiation in tropical ants-can they explain local ant coexistence? Biotropica 47:208-217. https://doi.org/10.1111/ btp. 12184 
Houadria M, Blüthgen N, Salas-Lopez A et al (2016) The relation between circadian asynchrony, functional redundancy, and trophic performance in tropical ant communities. Ecology 97:225-235

Human KG, Gordon DM (1996) Exploitation and interference competition between the invasive Argentine ant, Linepithema humile, and native ant species. Oecologia 105:405-412. https://doi. org/10.1007/BF00328744

I'Anson Price R, Dulex N, Vial N et al (2019) Honeybees forage more successfully without the "dance language" in challenging environments. Sci Adv. https://doi.org/10.1126/sciadv.aat0450

Jarau S, Hrncir M (2009) Food exploitation by social insects. Taylor \& Francis Group, LLC, Philadelphia

Kaspari M, Weiser MD (2000) Ant activity along moisture gradients in a neotropical forest. Biotropica 32:703. https://doi. org/10.1646/0006-3606(2000)032[0703:aaamgi]2.0.co;2

Kaur R, Joseph J, Anoop K, Sumana A (2017) Characterization of recruitment through tandem running in an Indian queenless ant Diacamma indicum. R Soc Open Sci 4:160476. https://doi. org/10.1098/rsos.160476

Kendal RL, Coolen I, Laland KN (2004) The role of conformity in foraging when personal and social information conflict. Behav Ecol 15:269-277. https://doi.org/10.1093/beheco/arh008

Keppner EM, Jarau S (2016) Influence of climatic factors on the flight activity of the stingless bee Partamona orizabaensis and its competition behavior at food sources. J Comp Physiol A 202:691-699. https://doi.org/10.1007/s00359-016-1112-1

Lach L (2005) Interference and exploitation competition of three nectar-thieving invasive ant species. Insectes Soc 52:257-262. https ://doi.org/10.1007/s00040-005-0807-z

Lach L, Parr CL, Abbott KL (2010) Ant ecology. Oxford University Press Inc., New York

Lanan MC (2014) Spatiotemporal resource distribution and foraging strategies of ants (Hymenoptera: Formicidae). Myrmecol News 20:53-70. https://doi.org/10.1016/j.biotechadv.2011.08.021.Secre ted

Liefke C, Hölldobler B, Maschwitz U (2001) Recruitment behavior in the ant genus Polyrhachis (Hymenoptera, Formicidae). J Insect Behav 14:637-657

Möglich M, Maschwitz U, Hölldobler B (1974) Tandem calling: a new kind of signal in ant communication. Science (80-) 186:1046-1047

Nagamitsu T, Inoue T (1997) Aggressive foraging of social bees as a mechanism of floral resource partitioning in an Asian tropical rainforest. Oecologia 110:432-439

Narendra A, Alkaladi A, Raderschall A et al (2013) Compound eye adaptations for diurnal and nocturnal lifestyle in the intertidal ant, Polyrhachis sokolova. PLoS ONE 8:4-9. https://doi.org/10.1371/ journal.pone.0076015

Narendra A, Reid SF, Raderschall CA (2013) Navigational efficiency of nocturnal myrmecia ants suffers at low light levels. PLoS ONE 8:1-7. https://doi.org/10.1371/journal.pone.0058801
Narendra A, Kamhi JF, Ogawa Y (2017) Moving in dim light: behavioral and visual adaptations in nocturnal ants. Integr Comp Biol 57:1104-1116. https://doi.org/10.1093/icb/icx096

Nascimento FS, Souza DISA, Tannure-Nascimento IC, Dantas JO (2012) Social facilitation and food partitioning in the queenless ant Dinoponera quadriceps (Hymenoptera: Formicidae). J Nat Hist. https://doi.org/10.1080/00222933.2012.700333

Oster GF, Wilson EO (1978) Caste and ecology in the social insects. Princeton University Press, Princeton

R Core Team (2019). R: A language and environment for statistical computing. R Foundation for Statistical Computing, Vienna, Austria. https://www.R-project.org/

Rosumek F (2017) Natural history of ants: What we (do not) know about trophic and temopral niches of neotropical species. Sociobiology 64:244-255. https://doi.org/10.13102/sociobiology.v64i3 .1623

Schilman PE, Lighton JRB, Holway DA (2007) Water balance in the Argentine ant (Linepithema humile) compared with five common native ant species from southern California. Physiol Entomol 32:1-7. https://doi.org/10.1111/j.1365-3032.2006.00533.x

Schmidt C (2013) Molecular phylogenetics of ponerine ants (Hymenoptera: Formicidae: Ponerinae). Zootaxa 3647:201-250

Seeley TD (1995) The wisdom of the hive: the social physiology of honey bee colonies. Harvard University Press, Cambridge

Stuble KL, Rodriguez-Cabal MA, McCormick GL et al (2013) Tradeoffs, competition, and coexistence in eastern deciduous forest ant communities. Oecologia 171:981-992. https://doi.org/10.1007/ s00442-012-2459-9

Torres JA (1984) Niches and coexistence of ant communities in Puerto Rico: repeated patterns. Biotropica 16:284-295. https://doi. org/10.2307/2387937

Traniello JFA (1987) Comparative foraging ecology of north temperate ants: the role of worker size and cooperative foraging in prey selection. Insectes Soc 34:118-130. https://doi.org/10.1007/ BF02223830

Traniello JFA (1989) Foraging strategies of ants. Annu Rev Entomol 34:191-210. https://doi.org/10.1146/annurev.ento.34.1.191

Traniello JFA (1989) Chemical trail systems, orientation, and territorial interactions in the ant Lasius neoniger. J Insect Behav 2:339-354. https://doi.org/10.1007/BF01068060

Wheeler WM (1900) A study of some texan Ponerinae. Biol Bull $2: 1-31$

Wilson EO (1959) Communication by tandem running in the ant genus Cardiocondyla. Psyche 66:29-34

Zuur AF, Ieno EN, Walker NJ, Saveliev AA, Smith GM (2009) Mixed effects models and extensions in ecology with R. Springer, New York 